\title{
Patterns of medical care utilization according to environmental factors in asthma and chronic obstructive pulmonary disease patients
}

\author{
Eun-Jung Jo ${ }^{1,2,3}$, Min-Hyeok Choi ${ }^{4}$, Chang-Hoon Kim ${ }^{4}$, Kyung-Mi Won ${ }^{5}$, Yoo-Keun Kim ${ }^{6}$, Ju-Hee Jeong ${ }^{5}$, \\ Hye Yeon $\mathrm{An}^{6}$, Mi-Kyoung Hwang ${ }^{5}$, and Hye-Kyung Park ${ }^{1,2,3}$
}

\begin{abstract}
${ }^{1}$ Department of Internal Medicine, Pusan National University School of Medicine, Busan; ${ }^{2}$ Department of Internal Medicine, ${ }^{3}$ Biomedical Research Institute, Pusan National University Hospital, Busan; ${ }^{4}$ Department of Preventive and Occupational Medicine, Pusan National University School of Medicine, Busan; ${ }^{5}$ The Institute of Environmental Studies, ${ }^{6}$ Division of Earth Environmental System, Pusan National University, Busan, Korea
\end{abstract}

Received: April 23, 2020 Revised : June 20, 2020 Accepted: July 2, 2020

\section{Correspondence to Hye-Kyung Park, M.D. Department of Internal Medicine, Pusan National University Hospital, 179 Gudeok- ro, Seo-gu, Busan 49241, Korea Tel: $+82-51-240-7225$ \\ Fax: +82-51-254-3127 \\ E-mail: parkhk@pusan.ac.kr https://orcid.org/0000-0003- 4065-2962}

Background/Aims: Weather and air pollution are associated with the exacerbation of respiratory diseases. We investigated patterns of medical care use according to meteorological factors and air pollution in patients with asthma or chronic obstructive pulmonary disease (COPD).

Methods: We analyzed the medical care utilization patterns of patients with asthma or COPD registered in the Korea Health Insurance Review and Assessment database for the period 2007 to 2013 . The patterns were divided into hospitalization and emergency department (ED) use.

Results: The medical care use of patients with asthma or COPD increased when the mean temperature and relative humidity were lower, and the temperature difference and atmospheric pressure were greater. Medical care use increased with the concentrations of particulate matter and ozone. Among age groups, sensitivity to pollutants was greatest in patients aged $\geq 65$ years. The effect of being elderly was greater for asthma than for COPD, with a higher hospitalization rate. ED utilization affected by environmental factors was significantly greater for females and hospitalization was significantly more common for males.

Conclusions: Meteorological factors and air pollutants were shown to contribute to increased medical care utilization by patients with asthma and COPD, particularly elderly patients. The overall effect was greater for COPD, but the effect in elderly patients was greater for asthma. In addition, the patterns of change in medical care use due to environmental factors differed according to sex.

Keywords: Weather; Air pollution; Asthma; Pulmonary disease, chronic obstructive; Health care utilization

\section{INTRODUCTION}

Health is affected by multilevel influences, such as weather, air pollution, and housing patterns, and by personal factors, such as age, sex, smoking, alcohol consumption. Weather changes and exposure to air pollution are associated with the development of new diseas- es and exacerbation of chronic diseases [1]. Uncontrolled chronic disease increases health care utilization and medical costs [2]. Thus, interventions for environmental and personal life management are needed for the proper management of chronic diseases.

Asthma and chronic obstructive pulmonary disease (COPD) are chronic respiratory diseases involving ob- 
structive ventilatory defects, and they are known to be aggravated by changes in weather and air pollution. High concentrations of particulate matter (PM) and ozone $\left(\mathrm{O}_{3}\right)$ exposure result in more emergency department (ED) visits and hospitalizations due to the exacerbation of asthma [3-6]. In addition, hospitalization due to the worsening of COPD increases with the concentrations of PM, sulfur dioxide, nitrogen dioxide, and atmospheric $\mathrm{O}_{3}$ [7]. Low temperature and humidity, high atmospheric pressure, and strong winds have been reported to be associated with worsening of asthma symptoms [810]. Thus, patients' appropriate responses to changes in weather and air pollution are important for the management of their respiratory diseases. In addition, knowledge of the personal characteristics of patients who are more vulnerable to environmental factors would facilitate the development of appropriate interventions. This study was conducted to examine patterns of medical care utilization according to meteorological factors and air pollution in patients with asthma or COPD.

\section{METHODS}

\section{Study population}

Data on the medical care utilization patterns of patients with asthma or COPD in Busan, Ulsan, and Gyeongsangnam-do for the period 2007 to 2013 were extracted from the Korea Health Insurance Review and Assessment (HIRA) database. The data included the dates of medical care service use, patient age and sex, place of residence, and diagnostic codes (1oth revision of the International Classification of Diseases [ICD-10] codes) associated with each medical care visit. The diagnostic codes for asthma and COPD use were extracted, and medical care utilization was classified as hospitalization and ED use. To ensure diagnostic accuracy, only patients diagnosed with asthma or COPD based on the Chronic Condition Data Warehouse (CCW) algorithm were included in the analyses [11]. According to the CCW algorithm, the diagnosis of asthma or COPD can be confirmed by a history of at least one hospitalization or two outpatient claims with an ICD-10 code for asthma (J45 or J46) or COPD (J40 to J44) recorded in the hospital medical records in the previous year. Patients were grouped by age (o to 9,10 to 29,30 to 44,45 to 64 , and $\geq 65$ years) for identification of susceptible age groups.

This study was approved by the Institutional Review Board of Pusan National University Hospital (IRB no. H-2004-010-089). All personal identifying information for the included patients was anonymous; therefore, informed consent for this study was waived by the board.

\section{Air pollution and meteorological data}

Air quality indicators included daily means of hourly concentrations of PM with aerodynamic diameters < $10 \mu \mathrm{m}\left(\mathrm{PM}_{10}\right)$ and the highest average concentration of $\mathrm{O}_{3}$ for an 8-hour period (where there are large fluctuations throughout the day). As the $\mathrm{O}_{3}$ concentration can vary seasonally, $\mathrm{O}_{3}$ levels for May to September, when the concentration is expected to be relatively high, were included in the analyses. For the determination of individuals' air pollution exposure, subjects' residence locations were confirmed and values from the nearest measurement stations were used.

Meteorological observation data according to place of residence, obtained from the nearest monitoring station, were provided by the Korean Meteorological Administration and included mean temperature $\left({ }^{\circ} \mathrm{C}\right)$, temperature difference $\left({ }^{\circ} \mathrm{C}\right)$, wind speed $(\mathrm{m} / \mathrm{sec})$, relative humidity (\%), and atmospheric pressure $(\mathrm{hPa})$.

\section{Statistical analysis}

Statistical analyses were performed using SAS version 9.4 (SAS Institute, Cary, NC, USA) and Stata software version 15.0 (StataCorp LLC, College Station, TX, USA). Multilevel Poisson regression analysis was performed to examine associations of daily weather and air quality parameters with patients' health care utilization, taking into consideration age and sex distributions, and the place of residence. The regression results are presented as incidence rate ratios (IRRs). We performed receiver operating characteristic (ROC) analysis to compare the concentrations of $\mathrm{PM}$ and $\mathrm{O}_{3}$ when patients visited the ED against the respective standards provided by the World Health Organization (WHO); this was important because patient condition can deteriorate due to such environmental factors. In addition, we examined whether there were differences in the influence of environmental factors between the diseases. In all analyses, $p$ $<0.05$ was taken to indicate statistical significance. 


\section{RESULTS}

\section{Clinical characteristics of the study subjects}

The total number of medical care visits in Busan, Ulsan, and Gyeongsangnam-do for the period 2007 to 2013 was 434,008,772, including 147,910 (0.03\%) for asthma and 229,133 (0.05\%) for COPD management. Medical care visits were more prevalent among female patients (asthma, 54.8\%; COPD, 55.6\%) (Tables 1 and 2). Medical care use due to asthma was most prevalent among patients aged $\geq 65$ years, followed by those aged 45 to 64 and 0 to 9 years (Table 1). Medical care use due to COPD was prevalent in the 45 to 64 and $\geq 65$ years age groups (Table 2). With regard to place of residence, asthma accounted for a large proportion of medical care visits in Gyeongsangnam-do, while COPD accounted for the largest proportion in Busan (Tables 1 and 2).

\section{Weather and air pollution}

Table 3 shows the data on environmental factors. During the study period, the mean temperature was $14.1^{\circ} \mathrm{C} \pm$ $9.1^{\circ} \mathrm{C}$ (range, -11.3 to 34.0 ); the mean temperature difference was $9.3^{\circ} \mathrm{C} \pm 4.1^{\circ} \mathrm{C}$ (range, 0.1 to 28.8 ), and the mean wind speed was $2.3 \pm 1.4 \mathrm{~m} / \mathrm{sec}$ (range, o to 16.1 ). The

Table 1. Clinical characteristics of patients with asthma

\begin{tabular}{lccc}
\hline Characteristic & $\begin{array}{c}\text { Total } \\
(\mathrm{n}=147,910)\end{array}$ & $\begin{array}{c}\text { Hospitalization } \\
(\mathrm{n}=4,090)\end{array}$ & $\begin{array}{c}\text { Emergency department use } \\
(\mathrm{n}=72,601)\end{array}$ \\
\hline $\begin{array}{l}\text { Female sex } \\
\text { Age, yr }\end{array}$ & $80,995(54.8)$ & $2,045(50.0)$ & $41,973(57.8)$ \\
$0-9$ & $23,109(15.6)$ & $277(6.8)$ & $7,928(10.9)$ \\
$10-29$ & $13,322(9.0)$ & $174(4.3)$ & $5,200(7.2)$ \\
$30-44$ & $13,913(9.4)$ & $180(4.4)$ & $6,316(8.7)$ \\
$45-64$ & $38,080(25.7)$ & $753(18.4)$ & $20,994(28.9)$ \\
$\geq 65$ & $59,486(40.2)$ & $2,706(66.2)$ & $32,163(44.3)$ \\
Residence & & & $28,020(38.6)$ \\
Busan & $61,750(41.7)$ & $1,583(38.7)$ & $11,028(15.2)$ \\
Ulsan & $22,891(15.5)$ & $509(12.4)$ & $33,553(46.2)$ \\
\hline Gyeongsangnam-do & $63,269(42.8)$ & $1,998(48.9)$ & \\
\hline
\end{tabular}

Values are presented as number (\%).

Table 2. Clinical characteristics of patients with chronic obstructive pulmonary disease

\begin{tabular}{lccc}
\hline Characteristic & $\begin{array}{c}\text { Total } \\
(\mathrm{n}=229,133)\end{array}$ & $\begin{array}{c}\text { Hospitalization } \\
(\mathrm{n}=4,522)\end{array}$ & $\begin{array}{c}\text { Emergency department use } \\
(\mathrm{n}=115,489)\end{array}$ \\
\hline $\begin{array}{l}\text { Female sex } \\
\text { Age, yr }\end{array}$ & $127,422(55.6)$ & $2,111(46.7)$ & $66,218(57.3)$ \\
$0-9$ & $7,930(3.4)$ & $22(0.5)$ & $1,038(0.9)$ \\
$10-29$ & $27,777(12.1)$ & $237(5.2)$ & $11,393(9.9)$ \\
$30-44$ & $39,287(17.1)$ & $460(10.2)$ & $18,474(16.0)$ \\
$45-64$ & $77,227(33.7)$ & $1,267(28.0)$ & $43,663(37.8)$ \\
$\geq 65$ & $76,912(33.6)$ & $2,536(56.1)$ & $40,921(35.4)$ \\
Residence & & & $1,725(38.2)$ \\
Busan & $114,267(49.9)$ & $607(13.4)$ & $55,558(48.1)$ \\
Ulsan & $30,690(13.4)$ & $2,190(48.4)$ & $15,660(13.6)$ \\
Gyeongsangnam-do & $84,176(36.7)$ & & $44,271(38.3)$ \\
\hline
\end{tabular}

Values are presented as number (\%). 
Table 3. Distribution of environmental factors

\begin{tabular}{|c|c|c|c|c|c|c|c|}
\hline Variable & Mean \pm SD & Minimum & $\begin{array}{c}\text { Lower } \\
\text { quartile, Q1 }\end{array}$ & Median & $\begin{array}{c}\text { Upper } \\
\text { quartile, Q3 }\end{array}$ & Maximum & $\begin{array}{l}\text { Range, } \\
\text { Q3-Q1 }\end{array}$ \\
\hline Mean temperature, ${ }^{\circ} \mathrm{C}$ & $14.1 \pm 9.1$ & -11.3 & 6.5 & 15.0 & 21.8 & 34.0 & $15 \cdot 3$ \\
\hline Temperature difference, ${ }^{\circ} \mathrm{C}$ & $9 \cdot 3 \pm 4 \cdot 1$ & 0.1 & 6.4 & 8.8 & 11.6 & 28.8 & 5.2 \\
\hline Wind speed, $\mathrm{m} / \mathrm{sec}$ & $2.3 \pm 1.4$ & o & 1.3 & 1.9 & 2.8 & 16.1 & 1.5 \\
\hline Relative humidity, \% & $63.1 \pm 17.0$ & 11.3 & 50.4 & $65 \cdot 3$ & 76 & 100 & 25.6 \\
\hline Atmospheric pressure, hPa & $1,008.9 \pm 8.4$ & 968.8 & $1,003 \cdot 3$ & $1,009.1$ & 1,015 & $1,033.1$ & 11.7 \\
\hline $\mathrm{PM}_{10}, \mu \mathrm{g} / \mathrm{m}^{3}$ & $48.7 \pm 33.6$ & o & 31.2 & 42.9 & 58.8 & $1,548.2$ & 27.6 \\
\hline $\mathrm{O}_{3}, \mathrm{ppb}$ & $39.2 \pm 16.4$ & 1 & 27.7 & $37 \cdot 3$ & 48.9 & 153.1 & 21.2 \\
\hline
\end{tabular}

$\mathrm{PM}$, particulate matter; $\mathrm{O}_{3}$, ozone.

Table 4. Effects of weather and air pollutants on medical utilization patterns

\begin{tabular}{|c|c|c|c|c|}
\hline \multirow[b]{2}{*}{ Variable } & \multicolumn{2}{|c|}{ Asthma } & \multicolumn{2}{|c|}{ COPD } \\
\hline & Hospitalization & $\begin{array}{c}\text { Emergency } \\
\text { department use }\end{array}$ & Hospitalization & $\begin{array}{c}\text { Emergency } \\
\text { department use }\end{array}$ \\
\hline Mean temperature, ${ }^{\circ} \mathrm{C}$ & $0.988^{\mathrm{a}}(0.985-0.991)$ & $0.984^{\mathrm{a}}(0.983-0.984)$ & $0.983^{a}(0.980-0.986)$ & $0.973^{\mathrm{a}}(0.973-0.974)$ \\
\hline Temperature difference, ${ }^{\circ} \mathrm{C}$ & $1.027^{\mathrm{a}}(1.018-1.036)$ & $1.019^{\mathrm{a}}(1.017-1.022)$ & $1.018^{\mathrm{a}}(1.009-1.027)$ & $1.025^{\mathrm{a}}(1.023-1.027)$ \\
\hline Wind speed, $\mathrm{m} / \mathrm{sec}$ & $1.025(0.994-1.056)$ & $1.003(0.995-1.011)$ & $1.040^{\mathrm{a}}(1.011-1.070)$ & $1.024^{\mathrm{a}}(1.018-1.030)$ \\
\hline Relative humidity, \% & $0.996^{\mathrm{a}}(0.994-0.998)$ & $0.994^{\mathrm{a}}(0.994-0.995)$ & $0.995^{\mathrm{a}}(0.993-0.996)$ & $0.990^{\mathrm{a}}(0.990-0.990)$ \\
\hline Atmospheric pressure, $\mathrm{hPa}$ & $1.007^{\mathrm{a}}(1.003-1.011)$ & $1.016^{\mathrm{a}}(1.015-1.017)$ & $1.010^{\mathrm{a}}(1.006-1.014)$ & $1.027^{\mathrm{a}}(1.026-1.027)$ \\
\hline $\mathrm{PM}_{10}, \mu \mathrm{g} / \mathrm{m}^{3}$ & $1.001^{\mathrm{a}}(1.000-1.002)$ & $1.001^{\mathrm{b}}(1.001-1.001)$ & $1.001^{\mathrm{a}}(1.001-1.002)$ & $1.001^{\mathrm{a}}(1.001-1.001)$ \\
\hline $\mathrm{O}_{3}, \mathrm{ppb}$ & $1.000(0.997-1.003)$ & $1.002^{\mathrm{a}}(1.001-.003)$ & $1.001(0.998-1.004)$ & $1.005^{\mathrm{a}}(1.004-1.005)$ \\
\hline
\end{tabular}

Values are presented as incidence rate ratio (95\% confidence interval).

COPD, chronic obstructive pulmonary disease; $\mathrm{PM}$, particulate matter; $\mathrm{O}_{3}$, ozone.

${ }^{\mathrm{a}} \mathrm{p}<0.001$.

$\mathrm{b} p<0.05$.

mean relative humidity was $63.1 \% \pm 17.0 \%$ (range, 11.3 to 100 ), and the mean atmospheric pressure was 1,008.9 \pm $8.4 \mathrm{hPa}$ (range, 968.8 to 1,033.1). Air quality, as indicated by the mean daily $\mathrm{PM}_{10}$ and $\mathrm{O}_{3}$ levels over an 8-hour period, was normal based on the daily exposure limits set by the WHO $\left(50 \mu \mathrm{g} / \mathrm{m}^{3}\right.$ and $0.05 \mathrm{ppm}$ for $\mathrm{PM}_{10}$ and $\mathrm{O}_{3}$, respectively), with values of $48.7 \pm 33.6 \mu \mathrm{g} / \mathrm{m}^{3}$ and $39.2 \pm$ $16.4 \mathrm{ppb}$, respectively.

\section{Effects of weather and air pollution on health care utilization patterns}

Age and sex-adjusted IRRs showed that increased medical care utilization due to environmental factors was associated significantly with decreases in mean temperature and relative humidity, and increases in temperature difference and atmospheric pressure (Table 4). A decrease in mean temperature by $1^{\circ} \mathrm{C}$ increased the rates of hospitalization due to asthma and COPD by $1.2 \%$ and $1.7 \%$, respectively, and increased ED use by $1.6 \%$ and $2.7 \%$, respectively. An increase in temperature difference of $1^{\circ} \mathrm{C}$ increased the rates of hospitalization due to asthma and COPD by $2.7 \%$ and $1.8 \%$, respectively, and increased ED use by $1.9 \%$ and $2.5 \%$, respectively. A $10 \%$ decrease in relative humidity was associated with increases of $4 \%$ and $6 \%$ in asthma admissions and ED use, respectively, and of $5 \%$ and $10 \%$ in COPD admissions and ED use, respectively. An increase in atmospheric pressure of $10 \mathrm{hPa}$ was associated with increases in asthma hospitalizations and ED use of $7 \%$ and $16 \%$, and of COPD admissions and ED use of $10 \%$ and $27 \%$, respectively. An increase in wind speed of $1 \mathrm{~m} / \mathrm{sec}$ was associated with a $4 \%$ increase in hospitalizations and a $2.4 \%$ increase in ED use due to COPD, but wind speed showed no association with admission or ED use related 


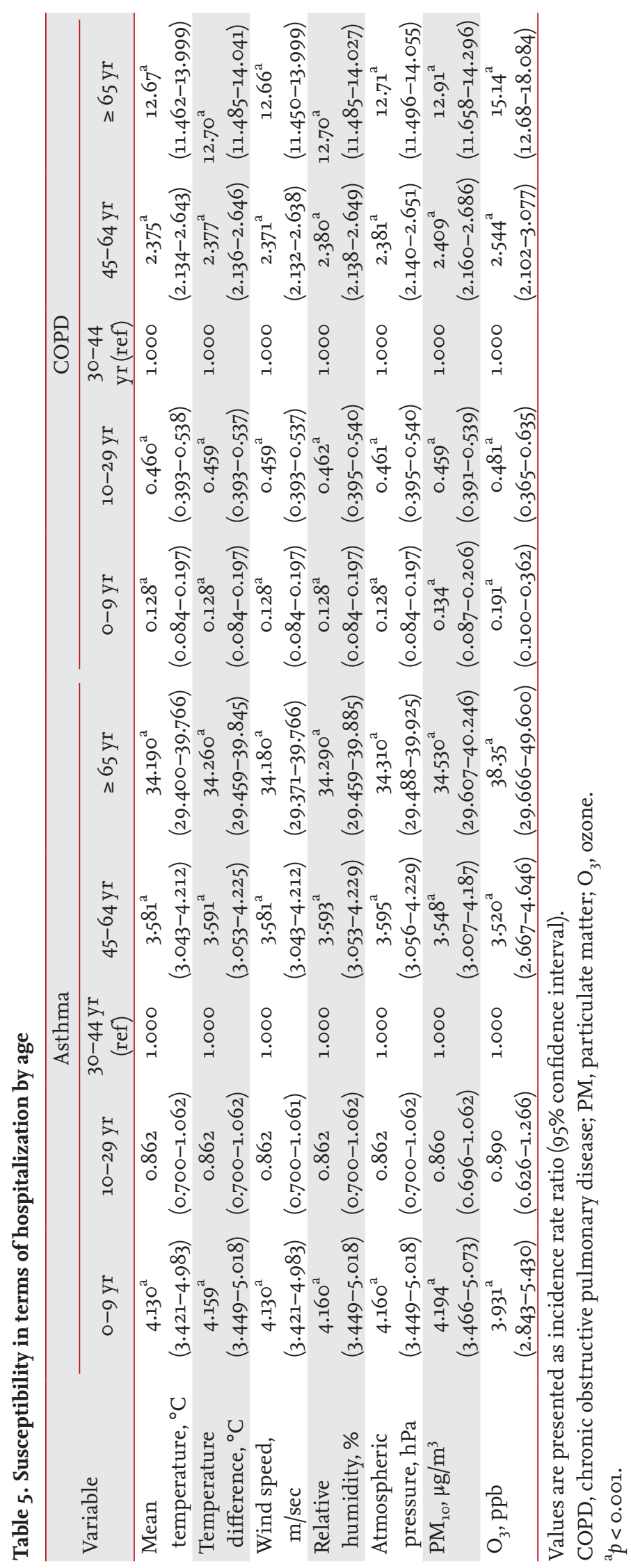

to asthma.

An increase in $\mathrm{PM}_{10}$ of $10 \mu \mathrm{g} / \mathrm{m}^{3}$ was associated with an increase of $1 \%$ in medical care visits for both asthma and COPD. In addition, an increase in the $\mathrm{O}_{3}$ level by $10 \mathrm{ppb}$ for the period May to September increased ED use for asthma and COPD by $2 \%$ and $5 \%$, respectively (Table 4 ). The increases in incidence of medical care use associated with changes in meteorological factors and air pollution concentrations were slightly greater for COPD than for asthma (Table 4).

\section{Susceptibility according to age}

The risk of increased medical care utilization for asthma was highest among elderly patients, followed by those aged o to 9 years (Tables 5 and 6). The effect on COPD was also significant in elderly patients (Tables 5 and 6). Hospitalization and emergency medical care visits decreased in patients with COPD aged below 30 years.

Both diseases were most affected in the elderly, but the effects of elderly asthma patients compared to young adults were greater than that of COPD (Tables 5 and 6).

\section{Susceptibility according to sex}

In both diseases, medical care use was more prevalent among female patients (Tables 1 and 2). The effects of environmental factors on hospitalization and ED use rates differed according to sex (Table 7). Overall, ED use due to environmental factors was more common in females, and hospitalization was more common in males.

\section{The values of environmental factors affecting emer- gency medical care use}

The values associated with disease worsening, evaluated by ROC analysis, are presented in Table 8. Mean temperature associated with exacerbation of asthma and COPD were $19.9^{\circ} \mathrm{C}$ for asthma and $20.2^{\circ} \mathrm{C}$ for COPD, relative humidity were $65.8 \%$ for asthma and $65.3 \%$ for COPD, and atmospheric pressure were 1,006.o hPa for asthma and 1,008.1 hPa for COPD. $\mathrm{PM}_{10}$ concentration were $46.0 \mu \mathrm{g} / \mathrm{m}^{3}$ for asthma and $53.5 \mu \mathrm{g} / \mathrm{m}^{3}$ for COPD, indicating that lower concentrations were associated with increased in medical care utilization for asthma. The WHO) criterion for $\mathrm{PM}_{10}$ and $\mathrm{O}_{3}$ is based on an upper limit of a 24-hour average concentration of $50 \mu \mathrm{g} / \mathrm{m}^{3}$ and 8-hour average concentration of $0.05 \mathrm{ppm}$, respectively. The $\mathrm{PM}_{10}$ concentration determined to increase 


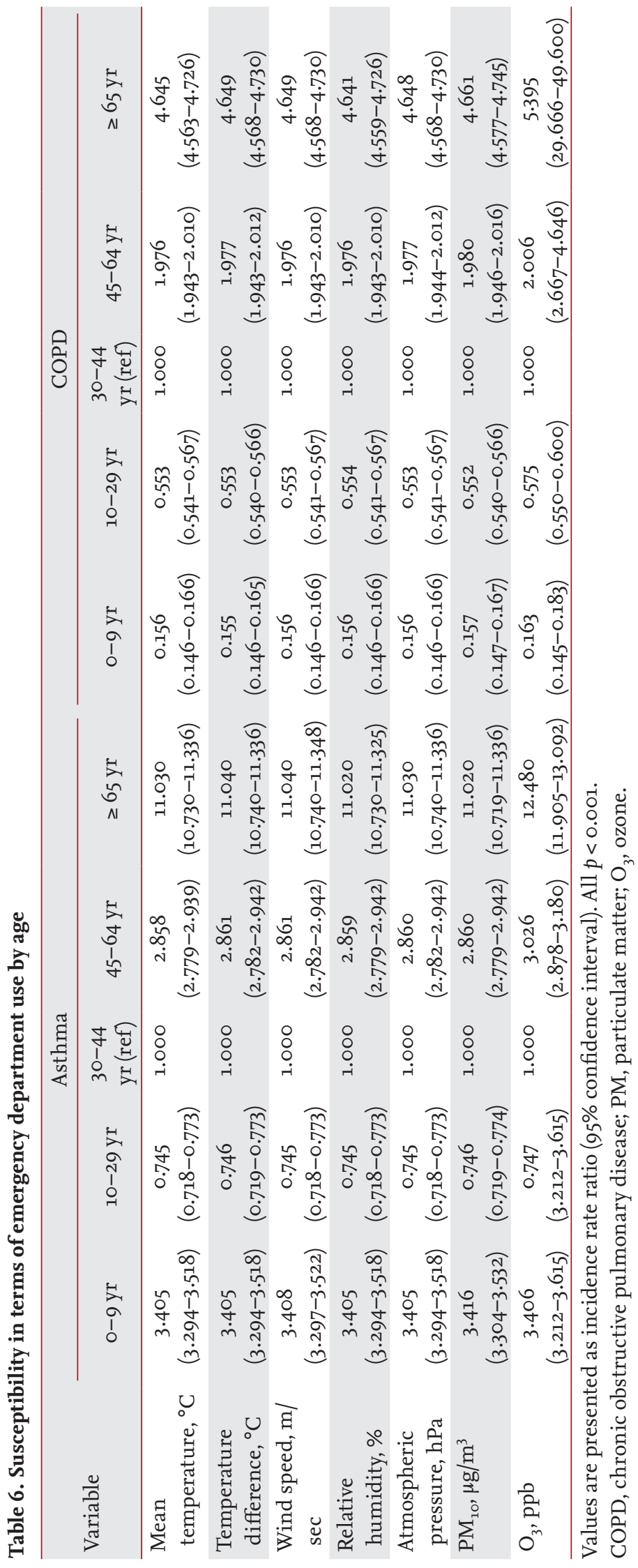

ED visits due to asthma was $45.9 \mu \mathrm{g} / \mathrm{m}^{3}$, which was lower than the value recommended by the WHO. On the other hand, the $\mathrm{O}_{3}$ concentration during the period May to September was found to affect the ED visits due to COPD even at relatively lower concentrations than the WHO's value.

\section{DISCUSSION}

This study showed that low temperature, low humidity, a large temperature difference, high atmospheric pressure, high wind speed, and high concentrations of $\mathrm{PM}_{10}$ and $\mathrm{O}_{3}$ were associated with increased use of medical care for asthma and COPD. Differences were observed in the effects of environmental factors on asthma and COPD, medical utilization patterns according to age, medical care use according to sex, and sensitivity values.

The effects of meteorological factors and environmental pollution on asthma and COPD are well known. Lower temperatures result in more asthma exacerbations [12,13], and COPD has been reported to be affected by high and low temperatures [14,15]. Large temperature differences, low humidity, high atmospheric pressure, and strong winds increase ED visits due to asthma exacerbation $[9,10,16,17]$. A study evaluating rates of hospitalization due to respiratory diseases in Busan, based on health insurance data, showed that increased PM concentrations were associated with increased rates of hospitalization due to respiratory diseases [18]. Furthermore, short-term exposure to high concentrations of PM resulted in increased ED visit and hospitalization rates due to the worsening of asthma symptoms [3,4]. COPD-related hospital visits, including admissions and outpatient clinic visits, increased by $0.25 \%$ to $0.26 \%$ for every $10 \mu \mathrm{g} / \mathrm{m}^{3} \mathrm{PM}[19]$. The effects of environmental factors on medical care use due to asthma and COPD in this study were similar to those reported in previous studies. However, we attempted to identify particular characteristics of asthma and COPD patients that were most strongly associated with the effects of environmental factors.

Asthma is characterized by reversible airflow restriction and respiratory symptoms reflecting chronic airway inflammation, and COPD is characterized by irreversible airflow limitation due to airway and lung parenchy- 
Table 7. Medical care use patterns among females (versus males)

\begin{tabular}{|c|c|c|c|c|}
\hline \multirow[b]{2}{*}{ Variable } & \multicolumn{2}{|c|}{ Asthma } & \multicolumn{2}{|c|}{ COPD } \\
\hline & Hospitalization & $\begin{array}{c}\text { Emergency } \\
\text { department use }\end{array}$ & Hospitalization & $\begin{array}{c}\text { Emergency } \\
\text { department use }\end{array}$ \\
\hline Mean temperature, ${ }^{\circ} \mathrm{C}$ & $0.761^{a}(0.715-0.810)$ & $1.165^{\mathrm{a}}(1.148-1.183)$ & $0.695^{\mathrm{a}}\left(0.655^{-0.737)}\right.$ & $1.181^{\mathrm{a}}(1.166-1.195)$ \\
\hline Temperature difference, ${ }^{\circ} \mathrm{C}$ & $0.762^{\mathrm{a}}(0.716-0.811)$ & $1.165^{\mathrm{a}}(1.148-1.183)$ & $0.695^{\mathrm{a}}\left(0.655^{-0.737)}\right.$ & $1.18 \mathrm{1}^{\mathrm{a}}(1.168-1.195)$ \\
\hline Wind speed, $\mathrm{m} / \mathrm{sec}$ & $0.760^{\mathrm{a}}(0.715-0.809)$ & $1.165^{\mathrm{a}}(1.148-1.183)$ & $0.695^{\mathrm{a}}\left(0.655^{-0.737)}\right.$ & $1.18 \mathrm{1}^{\mathrm{a}}(1.168-1.195)$ \\
\hline Relative humidity, \% & $0.762^{\mathrm{a}}(0.717-0.811)$ & $1.165^{\mathrm{a}}(1.148-1.183)$ & $0.694^{\mathrm{a}}(0.654-0.736)$ & $1.181^{\mathrm{a}}(1.168-1.195)$ \\
\hline Atmospheric pressure, $\mathrm{hPa}$ & $0.762^{\mathrm{a}}(0.717-0.811)$ & $1.165^{\mathrm{a}}(1.148-1.183)$ & $0.694^{\mathrm{a}}(0.654-0.736)$ & $1.18 \mathrm{1}^{\mathrm{a}}(1.166-1.195)$ \\
\hline $\mathrm{PM}_{10}, \mu \mathrm{g} / \mathrm{m}^{3}$ & $0.772^{\mathrm{a}}(0.725-0.822)$ & $1.174^{\mathrm{a}}(1.156-1.191)$ & $0.698^{\mathrm{a}}(0.658-0.741)$ & $1.184^{\mathrm{a}}(1.17-1.198)$ \\
\hline $\mathrm{O}_{3}, \mathrm{ppb}$ & $0.754^{\mathrm{a}}(0.681-0.835)$ & $1.137^{\mathrm{a}}(1.108-1.166)$ & $0.665^{\mathrm{a}}(0.602-0.736)$ & $1.148^{\mathrm{a}}(1.124-1.172)$ \\
\hline
\end{tabular}

Values are presented as incidence rate ratio (95\% confidence interval).

COPD, chronic obstructive pulmonary disease; $\mathrm{PM}$, particulate matter; $\mathrm{O}_{3}$, ozone.

${ }^{\mathrm{a}} \mathrm{p}<0.001$.

Table 8. Thresholds for effects of weather and air pollutants on emergency department use (ROC analysis)

\begin{tabular}{|c|c|c|c|c|c|c|}
\hline \multirow{2}{*}{ Variable } & \multicolumn{3}{|c|}{ Asthma } & \multicolumn{3}{|c|}{ COPD } \\
\hline & Cutoff value & AUC & $p$ value & Cutoff value & AUC & $p$ value \\
\hline Mean temperature, ${ }^{\circ} \mathrm{C}$ & 19.9 & 0.541 & $<0.001$ & 20.2 & 0.569 & $<0.001$ \\
\hline Temperature difference, ${ }^{\circ} \mathrm{C}$ & 13.8 & 0.503 & $<0.001$ & 12.2 & 0.523 & $<0.001$ \\
\hline Wind speed, $\mathrm{m} / \mathrm{sec}$ & 2.9 & 0.508 & $<0.001$ & 1.8 & 0.529 & $<0.001$ \\
\hline Relative humidity, \% & 65.8 & 0.536 & $<0.001$ & $65 \cdot 3$ & 0.568 & $<0.001$ \\
\hline Atmospheric pressure, $\mathrm{hPa}$ & $1,006.0$ & 0.580 & $<0.001$ & $1,008.1$ & 0.595 & $<0.001$ \\
\hline $\mathrm{PM}_{10}, \mu \mathrm{g} / \mathrm{m}^{3}$ & 46.0 & 0.519 & $<0.001$ & $53 \cdot 5$ & 0.518 & $<0.001$ \\
\hline $\mathrm{O}_{3}, \mathrm{ppb}$ & $57 \cdot 5$ & 0.499 & 0.629 & $27 \cdot 5$ & 0.509 & 0.021 \\
\hline
\end{tabular}

ROC, receiver operating characteristic; COPD, chronic obstructive pulmonary disease; AUC, area under the curve; PM, particulate matter; $\mathrm{O}_{3}$, ozone.

mal damage caused by chronic inflammation. Common causes of the acute exacerbation of asthma and COPD are airway infections [20-23] and air pollution [24,25]. PM increases the concentrations of polymorphonuclear neutrophils, inflammatory mediators, such as interleukin (IL)- $1 \beta$, tumor necrosis factor- $\alpha$, IL-6, and IL-8, and chemokines, causing inflammatory reactions and increased mucus secretion [26-28]. In addition, strong oxidants cause lung damage and increase airway hyperresponsiveness, resulting in bronchial contraction. These changes can lead to obstruction of the bronchioles, which can reduce the forced expiratory volume in 1 second (FEV1) and cause shortness of breath [29]. Exposure to $\mathrm{O}_{3}$ causes airway hyperreactivity, lung hyperpermeability, inflammation, and cell damage, which may induce more exaggerated oxidative stress-associated asthma exacerbation [30]. Thus, exacerbation of asthma and COPD, as chronic respiratory diseases, by environmental factors is known to occur, but the effects of environmental factors on asthma and COPD have not been compared. Our study, which evaluated the medical care use patterns of asthma and COPD patients exposed to the same environmental factors, confirmed that medical care visits related to COPD increased slightly with exposure to environmental factors. Moreover, elderly asthma patients were more sensitive to environmental factors than elderly COPD patients.

Our study confirmed increases in medical care utilization for both diseases among patients aged $\geq 65$ years, with a greater effect seen for elderly asthma than for elderly COPD. Hospitalization rates also increased significantly among patients aged $\geq 65$ years. Elderly 
patients are greatly affected by environmental factors, which may lead to more severe exacerbations requiring hospitalization. In an analysis of health care utilization by elderly patients (age $\geq 65$ years) diagnosed with asthma or COPD in the period 1984 to 1991 in the USA, the duration and cost of hospitalization were greater for patients with COPD than for those with asthma [31]. Our study was unique in that it analyzed medical care utilization patterns according to environmental factors. COPD alone may have a higher hospitalization rate than asthma, but elderly asthma patients may be more sensitive to the effects of environmental factors. This latter finding may have been due to the inclusion of patients with asthma-COPD overlap syndrome (ACO) in the asthma cohort. Patients with ACO generally have been reported to experience more frequent exacerbations than elderly patients with either asthma or COPD alone [32,33]. As the diagnoses were based on diagnostic codes provided by HIRA, we were unable to distinguish ACO patients; therefore, relatively low diagnostic accuracy could have been a limitation of this study. Of course, ACO patients may also have been included in the COPD cohort. It is also possible that the COPD cohort included patients with relatively mild diseases, such as bronchitis, due to use of the CCW algorithm. Therefore, further studies are required with more accurate diagnoses. Despite these limitations, our study was valuable in that we compared the impact of environmental factors between two elderly disease groups; the results suggested a difference between the groups in terms of the extent to which they were influenced by environmental factors.

The frequency of ED visits was greater for females, and that of hospitalizations was greater for males. These results suggested that many exacerbations requiring hospitalization occurred in males. Singh et al. [34] showed that adult males had more severe acute asthma exacerbations than adult females, although females were admitted to the hospital twice as often. Hopke et al. [35] also reported female predominance of ED visits (discharge without hospitalization) for asthma. de Torres et al. [36] reported that women with COPD had more exacerbations than men, but found no difference in the hospitalization rate between the sexes, suggesting that women's symptomatic exacerbations requiring medical attention were not severe enough to require hospital admission. However, some authors have reported that female sex is a protective factor against ED visitation among patients with COPD [35,37]. Therefore, women may be more sensitive to the exacerbation of respiratory symptoms, leading to increased use of ED facilities, although the reported associations have been somewhat inconsistent for COPD, and severe deterioration requiring hospitalization for chronic respiratory diseases may be more frequent in men.

We examined the extent to which environmental factors worsened disease by ROC analysis. The WHO criterion for $\mathrm{PM}_{10}$ is based on an upper limit of a 24-hour average concentration of $50 \mu \mathrm{g} / \mathrm{m}^{3}$. In this study, the $\mathrm{PM}_{10}$ level determined to increase $\mathrm{ED}$ visits due to asthma was $45.9 \mu \mathrm{g} / \mathrm{m}^{3}$, which was lower than both the WHO value and the value for COPD. In previous studies, the effects of environmental factors were estimated by dividing the distributions of values for weather or air pollutant variables [38]. We attempted to identify the levels affected by environmental factors by ROC analysis. We recognize that these values are unreliable, as we did not evaluate diagnostic test accuracy, and there were large interindividual variations in medical care use. However, this approach showed that the sensitivity to environmental factors may vary among diseases.

Our study had several limitations. The first was the limitation of diagnostic accuracy as mentioned above, as diagnoses were based on diagnostic codes extracted from the HIRA data. Second, we used mean $\mathrm{PM}_{10}$ and $\mathrm{O}_{3}$ values, although the effects of environmental factors may change frequently with changes in weather or air pollution. In the case of $\mathrm{O}_{3}$, the analysis period was set with consideration of the effects of season. In other study, $\mathrm{O}_{3}$ was analyzed only during the summer [38]. Both asthma and COPD tend to worsen during winter, so the effects of $\mathrm{O}_{3}$ were not analyzed over a period of 1 year instead being limited to the period May to September. That analysis indicated that the use of medical services for asthma and COPD increased with decreasing $\mathrm{O}_{3}$ concentration. It is thought that the influence of meteorological factors on disease course may be larger during periods of low $\mathrm{O}_{3}$ concentration. In addition, we did not conduct an analysis of delayed effects of environmental factors, where previous studies showed that the effects on COPD seems to be more delayed than those on asthma $[4,19,39]$. We treated each medical care visit as a discrete event; individuals making multiple vis- 
its were not distinguished. Although air pollution levels were analyzed according to place of residence in the regression analysis, actual exposure could differ markedly from daily average estimates, depending on factors such as time spent outside, place of work, and distance between the monitoring station and place of residence. If the distance between the measurement station and place of residence is large, actual exposure may be very different from the average estimate. Although the environmental factors in our study could not reflect actual exposure, our analysis was meaningful in that it took regional differences into consideration.

In summary, the results of this study demonstrated the impact of environmental factors on patients utilizing medical care services due to asthma and COPD. We confirmed that the influence of environmental factors differed by sex and age, and that sensitivity values differed between the two diseases. The environmental factors had a greater effect in elderly and female patients, although the hospitalization rate was higher for males. In addition, exacerbations differed between the diseases. These results suggested that environmental factors, such as temperature, humidity, and $\mathrm{O}_{3}$, can have an adverse effect on the disease course, but not in all patients. Individualized treatment and management has recently been emphasized for asthma and COPD; such treatment should take sex, age, and environmental factors into account.

\section{KEY MESSAGE}

1. Meteorological factors and air pollutants affected the rate of medical care utilization in patients with asthma and chronic obstructive pulmonary disease (COPD).

2. COPD was associated with more medical care visits due to environmental factors, but in elderly asthma, the increase in medical use is greater than in COPD.

3. Females may be more sensitive to environmental factors, with greater exacerbation of respiratory symptoms, although more exacerbations requiring hospitalization occurred in males.

4. Sensitivity to environmental factors may differ between diseases.

\section{Conflict of interest}

No potential conflict of interest relevant to this article was reported.

\section{Acknowledgments}

This work was funded by the Korea Meteorological Administration Research and Development Program under Grant KMI 2018-04212.

\section{REFERENCES}

1. Mannucci PM, Harari S, Martinelli I, Franchini M. Effects on health of air pollution: a narrative review. Intern Emerg Med 2015;10:657-662.

2. Guilbert TW, Garris C, Jhingran P, et al. Asthma that is not well-controlled is associated with increased healthcare utilization and decreased quality of life. J Asthma 2011;48:126-132.

3. Malig BJ, Green S, Basu R, Broadwin R. Coarse particles and respiratory emergency department visits in California. Am J Epidemiol 2013;178:58-69.

4. Silverman RA, Ito K. Age-related association of fine particles and ozone with severe acute asthma in New York City. J Allergy Clin Immunol 2010;125:367-373.

5. Lam HC, Li AM, Chan EY, Goggins WB 3rd. The shortterm association between asthma hospitalisations, ambient temperature, other meteorological factors and air pollutants in Hong Kong: a time-series study. Thorax 2016;71:1097-1109.

6. Mar TF, Koenig JQ. Relationship between visits to emergency departments for asthma and ozone exposure in greater Seattle, Washington. Ann Allergy Asthma Immunol 2009;103:474-479.

7. Ko FW, Tam W, Wong TW, et al. Temporal relationship between air pollutants and hospital admissions for chronic obstructive pulmonary disease in Hong Kong. Thorax 2007;62:780-785.

8. Rossi OV, Kinnula VL, Tienari J, Huhti E. Association of severe asthma attacks with weather, pollen, and air pollutants. Thorax 1993;48:244-248.

9. Ehara A, Takasaki H, Takeda Y, et al. Are high barometric pressure, low humidity and diurnal change of temperature related to the onset of asthmatic symptoms? Pediatr Int 2000;42:272-274.

10. Kwon JW, Han YJ, Oh MK, et al. Emergency department 
visits for asthma exacerbation due to weather conditions and air pollution in Chuncheon, Korea: a case-crossover analysis. Allergy Asthma Immunol Res 2016;8:512-521.

11. Centers for Medicare and Medicaid Services. Chronic Condition Data Warehouse 2014 [Internet]. Baltimore (MD): CCW, 2014 [cited 2021 Jan 5]. Available from: https:// www.ccwdata.org/web/guest/condition-categories.

12. Zhang Y, Peng L, Kan H, et al. Effects of meteorological factors on daily hospital admissions for asthma in adults: a time-series analysis. PLoS One 2014;9:e102475.

13. Son JY, Bell ML, Lee JT. The impact of heat, cold, and heat waves on hospital admissions in eight cities in Korea. Int J Biometeorol 2014;58:1893-1903.

14. Lin MT, Kor CT, Chang CC, et al. Association of meteorological factors and air $\mathrm{NO}_{2}$ and $\mathrm{O}_{3}$ concentrations with acute exacerbation of elderly chronic obstructive pulmonary disease. Sci Rep 2018;8:10192.

15. Hansel NN, McCormack MC, Kim V. The effects of air pollution and temperature on COPD. COPD 2016;13:372379.

16. Carey MJ, Cordon I. Asthma and climatic conditions: experience from Bermuda, an isolated island community. Br Med J (Clin Res Ed) 1986;293:843-844.

17. Villeneuve PJ, Leech J, Bourque D. Frequency of emergency room visits for childhood asthma in Ottawa, Canada: the role of weather. Int J Biometeorol 2005;50:48-56.

18. Jo EJ, Lee WS, Jo HY, et al. Effects of particulate matter on respiratory disease and the impact of meteorological factors in Busan, Korea. Respir Med 2017;124:79-87.

19. Jo YS, Lim MN, Han YJ, Kim WJ. Epidemiological study of PM2.5 and risk of COPD-related hospital visits in association with particle constituents in Chuncheon, Korea. Int J Chron Obstruct Pulmon Dis 2018;13:299-307.

20. Papi A, Bellettato CM, Braccioni F, et al. Infections and airway inflammation in chronic obstructive pulmonary disease severe exacerbations. Am J Respir Crit Care Med 2006;173:1114-1121.

21. Monso E, Ruiz J, Rosell A, et al. Bacterial infection in chronic obstructive pulmonary disease. A study of stable and exacerbated outpatients using the protected specimen brush. Am J Respir Crit Care Med 1995;152:1316-1320.

22. McManus TE, Marley AM, Baxter N, et al. Respiratory viral infection in exacerbations of COPD. Respir Med 2008;102:1575-1580.

23. Fagon JY, Chastre J, Trouillet JL, et al. Characterization of distal bronchial microflora during acute exacerbation of chronic bronchitis. Use of the protected specimen brush technique in 54 mechanically ventilated patients. Am Rev Respir Dis 1990;142:1004-1008.

24. Sint T, Donohue JF, Ghio AJ. Ambient air pollution particles and the acute exacerbation of chronic obstructive pulmonary disease. Inhal Toxicol 2008;20:25-29.

25. Peacock JL, Anderson HR, Bremner SA, et al. Outdoor air pollution and respiratory health in patients with COPD. Thorax 2011;66:591-596.

26. MacNee W, Donaldson K. Exacerbations of COPD: environmental mechanisms. Chest 2000;117:390S-397S.

27. Seaton A, MacNee W, Donaldson K, Godden D. Particulate air pollution and acute health effects. Lancet 1995;345:176178.

28. Utell MJ, Frampton MW. Acute health effects of ambient air pollution: the ultrafine particle hypothesis. J Aerosol Med 2000;13:355-359.

29. Anderson HR, Atkinson RW, Bremner SA, Marston L. Particulate air pollution and hospital admissions for cardiorespiratory diseases: are the elderly at greater risk? Eur Respir J Suppl 2003;40:39s-46s.

30. Duran CG, Burbank AJ, Mills KH, et al. A proof-of-concept clinical study examining the NRF2 activator sulforaphane against neutrophilic airway inflammation. Respir Res 2016;17:89.

31. Cydulka RK, McFadden ER Jr, Emerman CL, Sivinski LD, Pisanelli W, Rimm AA. Patterns of hospitalization in elderly patients with asthma and chronic obstructive pulmonary disease. Am J Respir Crit Care Med 1997;156:18071812.

32. Milanese M, Di Marco F, Corsico AG, et al. Asthma control in elderly asthmatics: an Italian observational study. Respir Med 2014;108:1091-1099.

33. Menezes AMB, Montes de Oca M, Perez-Padilla R, et al. Increased risk of exacerbation and hospitalization in subjects with an overlap phenotype: COPD-asthma. Chest 2014;145:297-304.

34. Singh AK, Cydulka RK, Stahmer SA, Woodruff PG, Camargo CA Jr. Sex differences among adults presenting to the emergency department with acute asthma. Multicenter Asthma Research Collaboration Investigators. Arch Intern Med 1999;159:1237-1243.

35. Hopke PK, Croft DP, Zhang W, et al. Changes in the hospitalization and ED visit rates for respiratory diseases associated with source-specific PM2.5 in New York State from 2005 to 2016. Environ Res 2020;181:108912. 
36. de Torres JP, Casanova C, Hernandez C, Abreu J, Aguirre-Jaime A, Celli BR. Gender and COPD in patients attending a pulmonary clinic. Chest 2005;128:2012-2016.

37. Kessler R, Faller M, Fourgaut G, Mennecier B, Weitzenblum E. Predictive factors of hospitalization for acute exacerbation in a series of 64 patients with chronic obstructive pulmonary disease. Am J Respir Crit Care Med 1999;159:158-164.
38. Kim SY, O'Neill MS, Lee JT, Cho Y, Kim J, Kim H. Air pollution, socioeconomic position, and emergency hospital visits for asthma in Seoul, Korea. Int Arch Occup Environ Health 2007;80:701-710.

39. Kim J, Kim H, Kweon J. Hourly differences in air pollution on the risk of asthma exacerbation. Environ Pollut 2015;203:15-21. 